
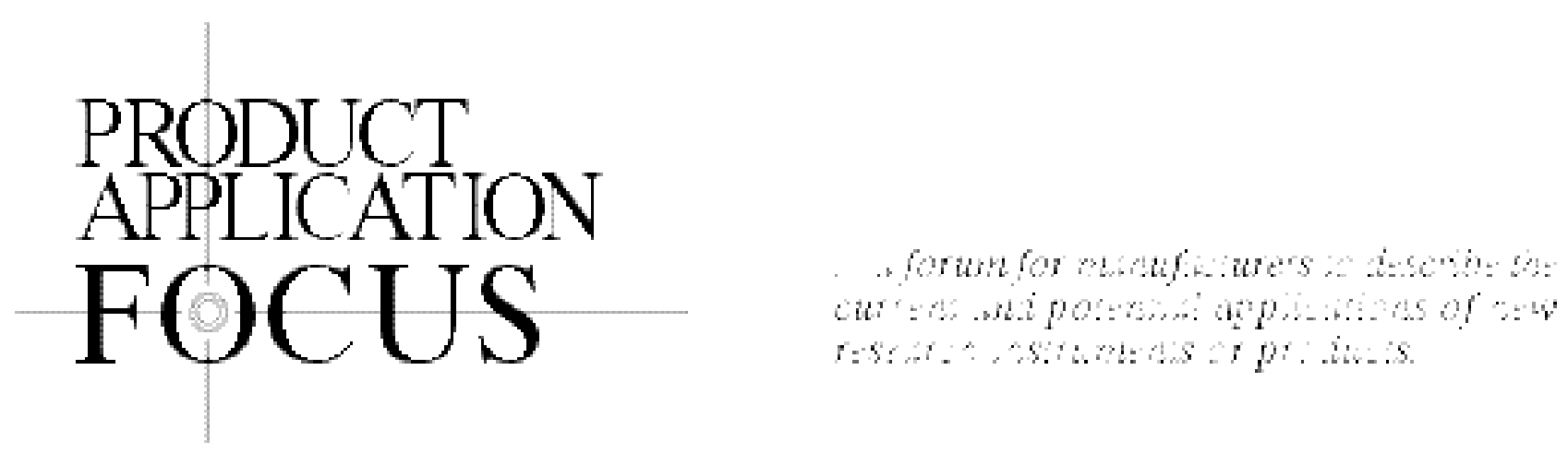

\title{
High-Speed Plasmid Isolation Using 96-Well, Size-Exclusion Filter Plates
}

\author{
D. Harris, M. Engelstein, R. Parry, J. Smith, M. Mabuchi, and J. Leonard \\ Millipore, Danvers, MA, USA
}

BioTechniques 32:626-631 (March 2002)

\begin{abstract}
The accelerating pace of genomics analysis has necessitated the abbreviation of DNA sample preparation protocols. We have developed a size-exclusion-based system for the rapid isolation of plasmid DNA in a 96-well microplate format. This high-speed protocol em ploys a modified alkaline lysis method for the preparation of the bacterial lysate, followed by three short vacuum filtration steps. Unlike traditional bind/wash/elute methods, there is no need to use chaotropic salts or ethanol. The samples are recovered from the top side of the MultiScreen $96{ }^{\circledR}$ PLASMID plates. Starting with bacterial cell pellets, the entire procedure for purifying the plasmid DNA can be performed in 30 min with a multichannel pipettor. The high yields, reproducibility, and quality of the plasmids make this system a good choice for any cloning or DNA sequencing operation.
\end{abstract}

\section{INTRODUCTION}

Since the introduction of the first rapid alkaline lysis method for the minipreparation of plasmid DNA (1), several variations on this technique have been developed and commercialized. Many existing methods for plasmid minipreparation in a 96well format make use of a silica matrix or glass fiber $(2,8)$ or an anion exchange matrix $(4,9)$ to which DNA is bound, followed by washing steps and elution. Methods that employ silica resin or fiber necessitate the use of hazardous, corrosive chaotropic agents and require ethanol to wash the DNA before elution of purified plasmids, while methods that use ion exchange media also require several washing steps to remove residual contaminants. These binding and washing steps often involve centrifugation and can be quite time consuming.

The MultiScreen ${ }_{96}{ }^{\circledR}$ PLASMID plates from Millipore (Bedford, MA, USA) utilize size-exclusion membrane tech- nology for the purification of plasmid DNA. Rather than binding the plasmid DNA to any type of matrix, it is simply retained on top of the size-exclusion membrane while proteins and contaminants in the bacterial lysates are filtered through to waste. There are two 96-well filter plates used in the procedure, one for the clarification of the crude bacterial lysate and the other for the retention of the plasmid DNA. Following three filtration steps, samples are suspended in buffer and recovered from the top side of the 96-well plate (Figure 1), which greatly enhances compatibility with automated systems. This procedure can be performed manually in $30 \mathrm{~min}$. This method generates sufficient quantities of plasmid DNA (3-6 $\mu \mathrm{g}$ ) for restriction analysis, cloning, PCR, transformation, and fluorescent dye-terminator sequencing. Since DNA sequencing is currently the predominant downstream application from plasmid DNA sample preparation, the critical test for the performance of plasmids generated by any purification system is the quality of the DNA sequence data. We have recently developed this system for plasmid purification using size-exclusion microplates, and we report that the plasmid DNA generated by this system provides superiorquality DNA sequence data. This new system for plasmid DNA purification is available in the Montage ${ }^{\mathrm{TM}}$ Plasmid Miniprep 96 Kit, which includes culture blocks and all of the devices and reagents required for purification of plamid DNA in a 96-well format.

\section{MATERIALS AND METHODS}

\section{Plasmid DNA Isolation}

The plasmid pLH2 is derived from pUC19 (2). The $2-\mathrm{kb}$ fragment of HindIII-digested $\lambda$ phage was cloned into the 
HindIII site of pUC19, resulting in a 4.7-kb plasmid. JM109 or XL1-blue cells were transformed with the pUC19 or pLH2 plasmids and streaked onto LB agar plates containing 100 $\mu \mathrm{g} / \mathrm{mL}$ ampicillin. Colonies were selected, and overnight cultures were grown in $2 \times \mathrm{LB}-\mathrm{Amp}(10 \mathrm{~g} / \mathrm{L}$ yeast extract, $20 \mathrm{~g} / \mathrm{L}$ tryptone, $5 \mathrm{~g} / \mathrm{L}$ sodium chloride, and $100 \mu \mathrm{g} / \mathrm{mL}$ ampicillin). The 96-well blocks (2.2-mL capacity) were seeded with 1$\mathrm{mL}$ aliquots of a 1:500 dilution of the overnight culture in $2 \times$ LB-Amp. The cultures were shaken for $24 \mathrm{~h}$ on an incubator shaker at 320 rpm (Innova ${ }^{\mathrm{TM}}$ 4080; New Brunswick Scientific, Edison, NJ, USA). After the appropriate dilution of the cultures, A measurements were taken at $650 \mathrm{~nm}$. The cultures revealed an A of approximately $4.0 \mathrm{U}$ at $650 \mathrm{~nm}$. The culture blocks were centrifuged at $1500 \times g$ for $10 \mathrm{~min}$, and the supernatant was decanted. The cell pellets were resuspended in 150 $\mu \mathrm{L}$ solution 1 (30 mM glucose, $15 \mathrm{mM}$ Tris- $\mathrm{HCl}, \mathrm{pH} 8.0,30$ $\mathrm{mM} \mathrm{Na} 2 \mathrm{EDTA}$, and $60 \mu \mathrm{g} / \mathrm{mL}$ RNase A) by shaking for 5 min on a plate shaker (setting no. 6, titer plate shaker, model no. 4625; Lab-Line Instruments, Melrose Park, IL, USA). The cells were lysed by adding $150 \mu \mathrm{L}$ solution $2(0.2 \mathrm{M}$ $\mathrm{NaOH}$ and $1 \%$ SDS) to each well of the 96-well block, shaking on the plate shaker for $1 \mathrm{~min}$, and incubating for an additional $2 \mathrm{~min}$. The samples were then neutralized by adding $150 \mu \mathrm{L}$ solution 3 (3.6 M K and $6 \mathrm{M}$ acetate, $\mathrm{pH}$ 5.7) to the wells and shaking on the plate shaker for $1 \mathrm{~min}$. The bacterial lysates were then ready for processing.

The lysate $(200 \mu \mathrm{L})$ was then transferred from the culture block to corresponding wells of the MultiScreen ${ }_{96}$ lysate clearing plate. The MultiScreen 96 PLASMID plate was placed inside the MultiScreen 96 vacuum manifold to collect the clarified bacterial lysates. The clearing plate containing the lysates was placed on top of the MultiScreen 96 manifold, and the vacuum was applied at 8 in $\mathrm{Hg}$ (270 mbar-203 torr) for $3 \mathrm{~min}$. Following this filtration step, the clearing plate was discarded, and the PLASMID plate containing the clarified lysates was transferred to the top of the vacuum manifold. The vacuum was applied at 24 in $\mathrm{Hg}$ ( 810 mbar-610 torr) for 5 min to filter the lysates, after which the vacuum was turned off. The plasmids were then washed by adding $200 \mu \mathrm{L}$ nuclease-free water to the wells of the PLASMID plate, and the vacuum was applied at $24 \mathrm{in} \mathrm{Hg}$ for $3.5 \mathrm{~min}$. At this point, the wells were empty, and the plasmid DNA was resuspended by adding $50 \mu \mathrm{L} 10 \mathrm{mM}$ Tris, $\mathrm{pH} 8.0$, and shaking on the titer plate shaker for $5 \mathrm{~min}$. Samples were pipetted into a 96-well, v-bottom microplate for storage and sealed with adhesive tape. An alternative protocol was also used in which $100 \mu \mathrm{L}$ solutions 1, 2, and 3 were used for the lysis steps, and the entire lysate volume was transferred into the clearing plate for processing. The filtration times for clearing, filtration, and washing were 7,8 , and $4 \mathrm{~min}$, respectively, using this alternative protocol. The plasmid DNA was quantitated by $\mathrm{A}_{260}$ using a SPECTRAmax ${ }^{\circledR}$ Plus plate reader (Molecular Devices, Sunnyvale, CA, USA), and the yields were confirmed by agarose gel analysis.

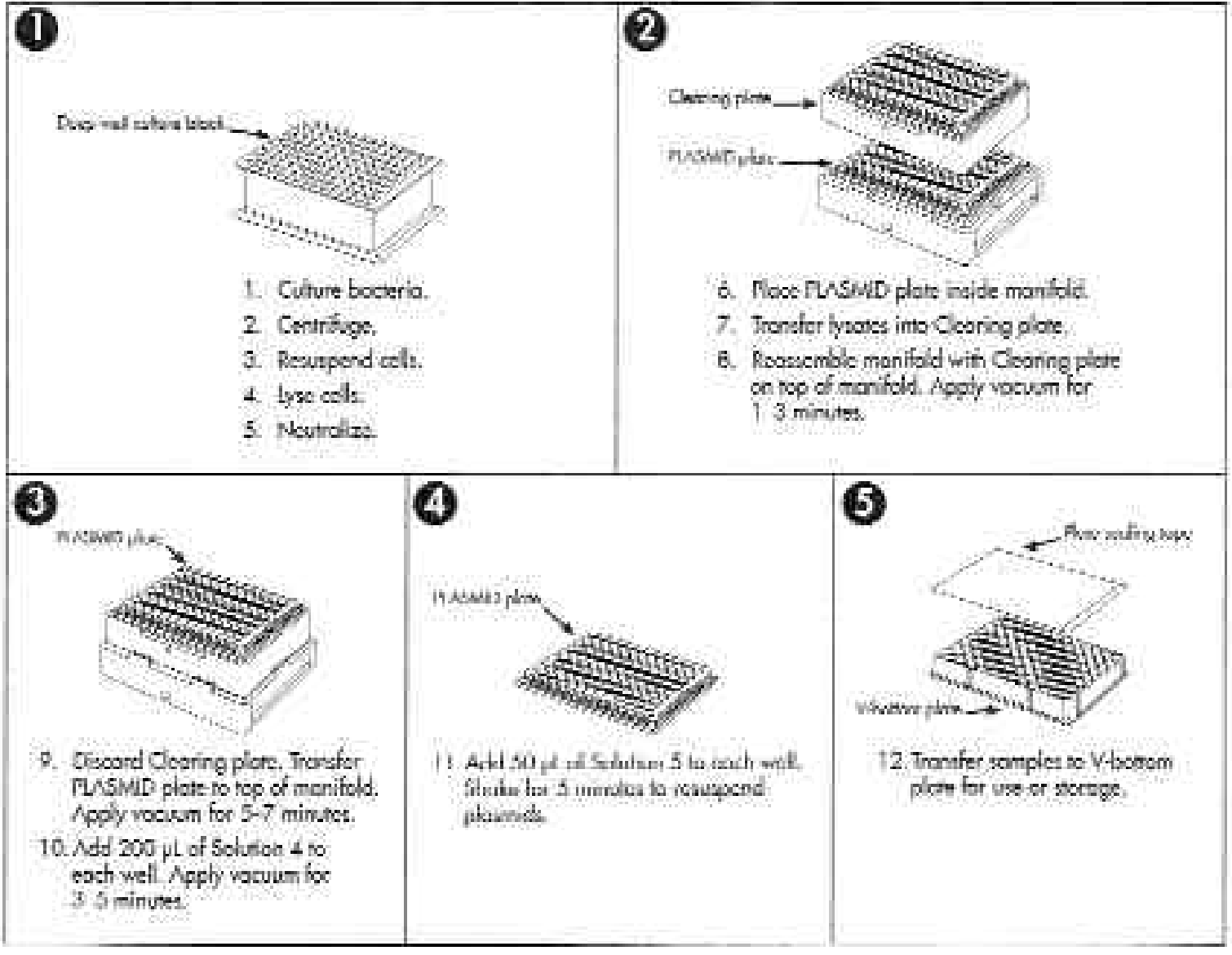

Figure 1. Illustration of size-exclusion-based plasmid purification procedure. 
Table 1. Typical Yields from MultiScreen ${ }_{96}$ PLASMID Plates

\begin{tabular}{|llll|}
\hline Host Strain & Plasmid & Protocol & Yield $(\mu \mathbf{g})$ \\
\hline XL1-Blue & pUC19 & Partial & $2.6 \pm 0.5$ \\
& & Full & $5.1 \pm 1.0$ \\
& pLH2a & Partial & $3.9 \pm 0.4$ \\
& & Full & $8.2 \pm 1.0$ \\
JM109 & pUC19 & Partial & $2.7 \pm 0.3$ \\
& & Full & $5.7 \pm 0.7$ \\
& pLH2a & Partial & $3.9 \pm 0.4$ \\
& & Full & $8.0 \pm 1.1$ \\
aThe plasmid pLH2 is derived from pUC19. The 2.0-kb \\
fragment of HindllI-digested $\lambda$ phage was cloned into the \\
Hindlll site of pUC19, resulting in a 4.7-kb plasmid.
\end{tabular}

\section{DNA Sequencing}

Miniaturized BigDye ${ }^{\circledR}$ version 1.0 (Applied Biosystems, Foster City, CA, USA) terminator reactions were used to sequence pUC19 and pLH2 plasmids. Reactions were set up and cycled as follows: each reaction consisted of $3 \mu \mathrm{L}$ pUC19 (100 ng) or $3 \mu \mathrm{L}$ pLH2 (160 ng) plasmid (pooled from a 96well preparation), $1 \mu \mathrm{L}$ M13-40 forward primer $(3 \mu \mathrm{M}), 0.5$ $\mu \mathrm{L}$ BigDye terminator mixture, and $0.75 \mu \mathrm{L} 5 \times$ buffer $(400$ $\mathrm{mM}$ Tris, $\mathrm{pH} 9.0,10 \mathrm{mM} \mathrm{MgCl} 2)$. Samples were cycled in a model 9600 thermal cycler (Perkin Elmer Life Science,

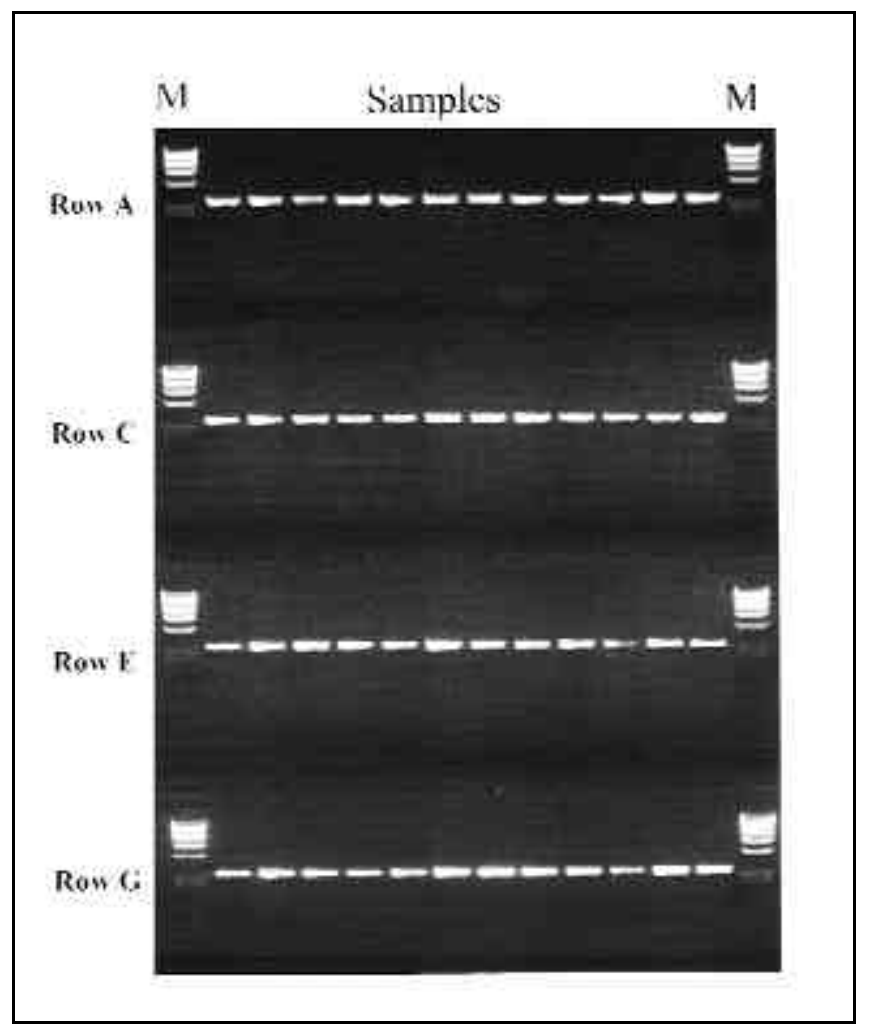

Figure 2. Agarose gel analysis of pLH2 plasmid purified using the Partial Lysate Protocol. Six microliters of purified plasmid were mixed with an equal volume of $2 \times$ loading dye and loaded onto a $1 \%$ agarose gel. We analyzed the plasmid DNA samples from rows A, C, E, and G of the preparation plate. The size markers flanking the plasmid samples are HindIII-digested $\lambda$ phage DNA.
Table 2. Sequence Data Quality Summary for Two Different Plasmids from Two Different Host Strains

\begin{tabular}{|c|c|c|c|}
\hline Host Strain & Plasmid & $\begin{array}{l}\text { Avg. read length } \\
n=24(>98 \% \\
\text { accuracy) }\end{array}$ & $\begin{array}{c}\text { Avg. phred } q \\
>20 \text { bases } \\
n=24\end{array}$ \\
\hline \multirow[t]{2}{*}{ XL1-Blue } & pUC19 & 707 & 618 \\
\hline & pLH2 & 658 & 623 \\
\hline \multirow[t]{2}{*}{ JM109 } & pUC19 & 706 & 602 \\
\hline & pLH2 & 695 & 543 \\
\hline \multicolumn{4}{|c|}{$\begin{array}{l}\text { All samples were prepared using the Partial Lysate } \\
\text { Protocol and were sequenced in } 1 / 16 \text { th BigDye sequenc- } \\
\text { ing reactions. Reactions were cleaned up using Multi- } \\
\text { Screen }{ }_{384}-S E Q \text { plates and were run on a MegaBACE } \\
1000 \text { capillary array sequencer. Either } 160 \text { ng pLH } 2 \text { or } 100 \\
\text { ng pUC } 19 \text { were used in the respective reactions. }\end{array}$} \\
\hline
\end{tabular}

Gaithersburg, MD, USA), according to the manufacturer's instructions. The sequencing reactions were cleaned up using MultiScreen $_{384}$-SEQ plates (Millipore) by adding $15 \mu \mathrm{L} 0.3$ mM EDTA to each $5-\mu \mathrm{L}$ reaction. The resulting $20-\mu \mathrm{L}$ reactions were then transferred from a 96-well thermal cycler plate to one quadrant of a MultiScreen $384^{-S E Q}$ plate using a Multimek96 ${ }^{\mathrm{TM}}$ liquid-handling system (Beckman Coulter, Miami, FL, USA). The MultiScreen $384^{-S E Q}$ plate was then placed on a MultiScreen 384 vacuum manifold (Millipore), and the samples were filtered at 25 in $\mathrm{Hg}$ for approximately 3 min. After the filtration was complete, the MultiScreen ${ }_{384^{-}}$ SEQ plate was returned to the deck of the Multimek96, and $25 \mu \mathrm{L} 0.3 \mathrm{mM}$ EDTA were added to all 384 wells of the plate. The MultiScreen $384^{-S E Q}$ plate was again transferred to the MultiScreen $_{384}$ vacuum manifold, and the samples were filtered at $25 \mathrm{in} \mathrm{Hg}$ for another $5 \mathrm{~min}$. Following this wash step, the samples were resuspended in $20 \mu \mathrm{L} 0.3 \mathrm{mM}$ EDTA by pipetting and transferred to a 96-well PCR plate (Robbins Scientific, Sunnyvale, CA, USA). From the plate, samples were injected into the MegaBACE ${ }^{\circledR} 1000$ (Amersham Biosciences, Piscataway, NJ, USA) capillary array sequencer. For analysis on the ABI PRIS ${ }^{\circledR} 3700$ (Applied Biosystems), the samples were transferred from the MultiScreen $384^{-S E Q}$ plate to a MicroAmp ${ }^{\circledR}$ 96-well reaction plate (Applied Biosystems), and the plate was sealed with adhesive foil before it was positioned on the deck of the instrument.

\section{RESULTS}

\section{Plasmid DNA Yields}

The protocol described here is designed to process only part of the bacterial lysate. Using only a portion of the entire lysate volume reduces the processing time at each filtration step, allowing the entire prepreparation to be performed in 30 min. This protocol, which we have termed the Partial Lysate Protocol, yields sufficient quantities of plasmid DNA for most applications, with minimal time and labor investment. However, it is possible to use smaller volumes of each of solutions 1,2 , and $3(100 \mu \mathrm{L})$ and then transfer the entire lysate volume into the MultiScreen ${ }_{96}$ clearing plate. This alternative protocol, the Full Lysate Protocol, results in only a minimal 
A)
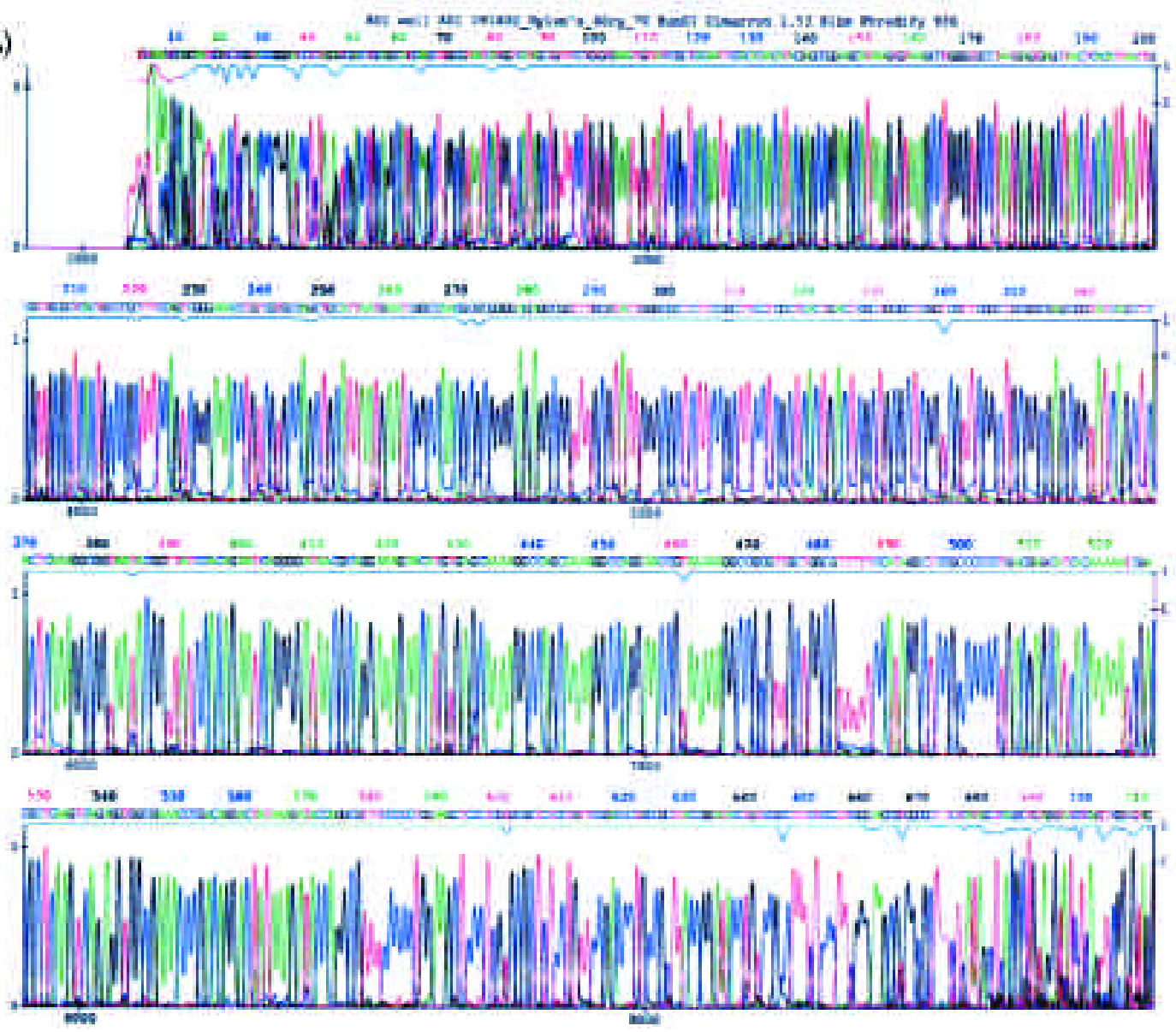

B)

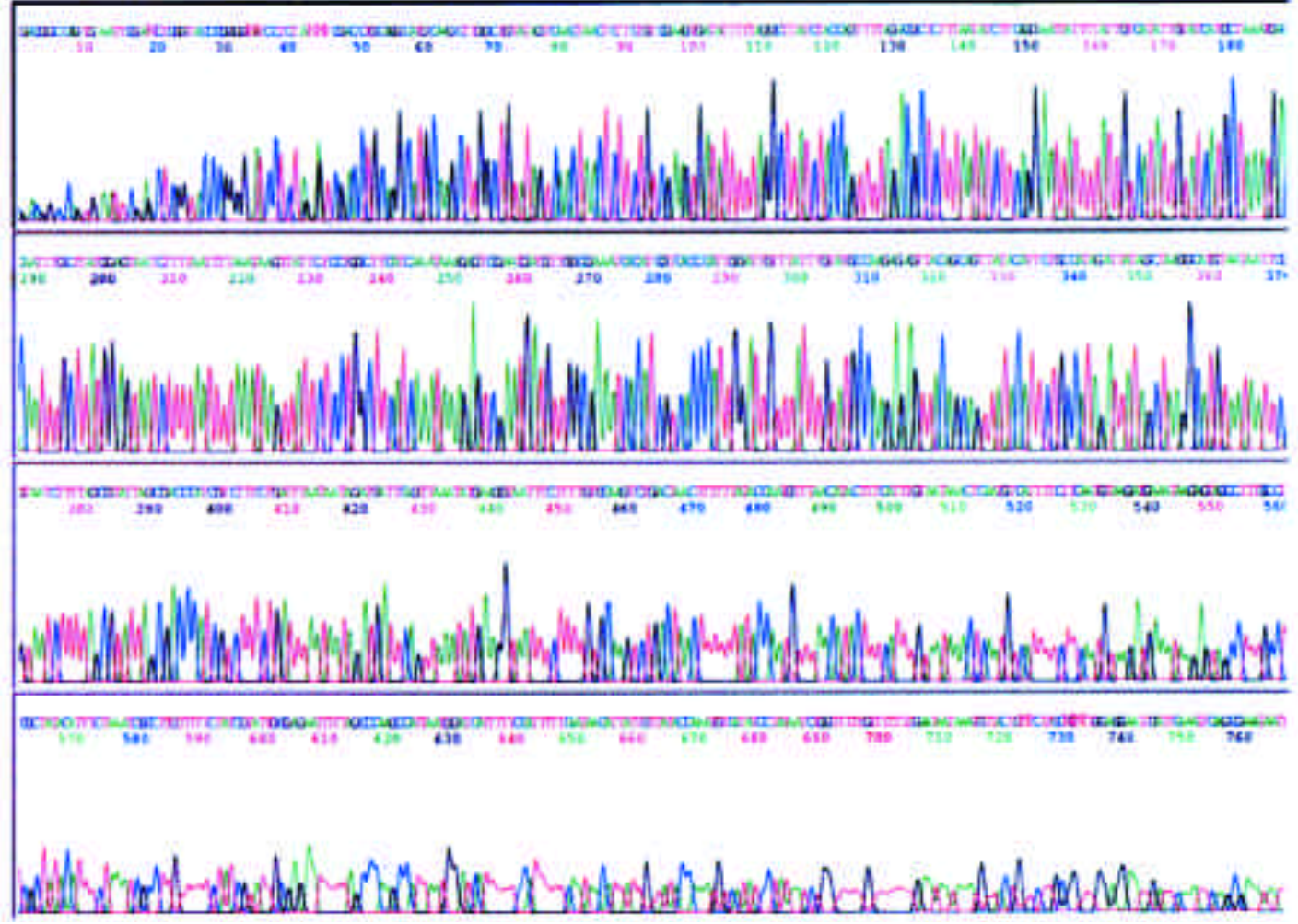

Figure 3. Electropherograms of sequence data acquired from both the MegaBACE 1000 and ABI PRISM3700 capillary array instruments. (A) Sequence of the pUC19 plasmid generated in a 1/16 scale BigDye version 1.0 terminator reaction, cleaned up on the MultiScreen $384^{-S E Q}$ plate, and injected into the MegaBACE 1000. The samples were run at $9 \mathrm{kV}$ for 120 min. Phred q > 20 of this sample was 678 bases. (B) Sequence of the pLH2 plasmid generated in a $1 / 16$ scale Big Dye version 1.0 terminator reaction, cleaned up on the MultiScreen 384 -SEQ plate, and injected into the ABI PRISM 3700 . The samples were run at $6.5 \mathrm{kV}$ for $117 \mathrm{~min}$. Phred $\mathrm{q}>20$ of this sample was 709 bases. 
increase in the total processing time ( $7-10 \mathrm{~min})$ and a significant increase in yields. The use of high copy number plasmids (7) maximizes yields with this system. Table 1 shows the typical yields achieved using both of these protocols. The agarose gel analysis in Figure 2 demonstrates the quality of the supercoiled plasmid DNA generated using our system and the preparation-to-preparation reproducibility. The 260/280 ratios of samples are consistently in the range of $1.8-1.9$, and the variation in yields across an entire 96-well plate prepared from a single clone is typically $8 \%-12 \%$ (data not shown).

\section{DNA Sequence Data}

We performed the sequencing of the plasmids purified with the MultiScreen96 PLASMID plate system using BigDye version 1.0 terminator chemistry and cleaned up the sequencing reactions with the MultiScreen $_{384^{-S E Q}}$ plates. These are 384-well plates specially designed for the removal of salts, dNTPs, and residual fluorescent dye-terminators after cycle sequencing. Following the cleanup of the reactions, the samples were injected into the MegaBACE 1000 or the ABI PRISM 3700 capillary array sequencers. The electropherograms in Figure 3 reveal that the plasmids generated by our system produce very high-quality sequence data on both of these instruments. Additionally, the quality of the plasmid DNA generated with this system facilitates miniaturization of fluorescent dye-terminator sequencing reactions. We have easily miniaturized BigDye terminator reactions using only $1 / 16$ of the manufacturer's recommended volume of the BigDye terminator mixture, without compromising the sequence quality and read lengths (Figure 3 ). Table 2 shows accurate $(>98 \%)$ read lengths beyond 700 bases and phred $q>20(5,6)$ of more than 600 bases are easily achieved under these conditions.

\section{DISCUSSION}

Our new plasmid purification system employs a modified version of the standard alkaline lysis procedure for the minipreparation of plasmid DNA. However, unlike methods in which plasmids are precipitated with ethanol or bound to silica and washed with ethanol, our procedure generates highpurity plasmid DNA using size-exclusion filter plates, eliminating the need for chaotropic salts and ethanol. This new approach to plasmid purification has several advantages over existing methods. First, the elimination of corrosive chaotropic agents and alcohols from the protocol reduces safety concerns and storage restrictions. Second, this protocol has fewer steps to follow than other plasmid minipreparation procedures, improving efficiency and increasing throughput. Third, the most important attribute of this system for high-throughput laboratories is the significant time savings in the preparation of plasmid DNA samples. Our system saves roughly 15 min per plate compared with other 96-well plasmid purification systems. Additionally, the MultiScreen 96 plates have a shorter profile than comparable bind/elute devices and reduce the consumption of plastics and save valuable storage space.

Harnessing our expertise in membrane technology, we have designed a new approach to plasmid DNA purification based on size exclusion. The cost of the materials for this protocol is competitive with existing methods, while the time required to process each 96-well plate is significantly less, in- creasing sample throughput and decreasing labor costs. In addition, the collection of purified samples is done by pipetting from the top of the MultiScreen plates, enhancing the compatibility with liquid-handling and robotic systems. The Montage Plasmid Miniprep ${ }_{96}$ Kit is a complete solution for highthroughput plasmid DNA preparation and is available in three package sizes (1-pack, 4-pack, and 24-pack). This size-exclusion platform for nucleic acid sample preparation has great utility for plasmid preparation as well as a wide range of other applications and will certainly assist high-throughput efforts in small and large genome research centers.

\section{ACKNOWLEDGMENT}

We would like to thank Joseph Hitti for critical reading of the manuscript.

\section{REFERENCES}

1.Birnboim, H.C. and J. Doly. 1979. A rapid alkaline extraction procedure for screening recombinant plasmid DNA. Nucleic Acids Res. 7:15131522 .

2.Engelstein, M., T.J. Aldredge, D. Madan, J.H. Smith, J.I. Mao, D.R. Smith, and P.W. Rice. 1998. An efficient, automatable template preparation for high-throughput sequencing. Microb. Comp. Genomics 3:237241.

3.Ewing, B. and P. Green. 1998. Base-calling of automated sequencer traces using phred. II. Error probabilities. Genome Res. 8:186-194.

4.Ewing, B., L. Hillier, M.C. Wendl, and P. Green. 1998. Base-calling of automated sequencer traces using phred. I. Accuracy assessment. Genome Res. 8:175-185.

5.Hawkins, T.L., T. O'Connor-Morin, A. Roy, and C. Santillan. 1994. DNA purification and isolation using a solid phase. Nucleic Acids Res. 22:4543-4544.

6.Itoh, M., P. Carninci, S. Nagaoka, N. Sasaki, Y. Okazaki, T. Ohsumi, M. Muramatsu, and Y. Hayashizaki. 1997. Simple and rapid preparation of plasmid template by a filtration method using microtiter filter plates. Nucleic Acids Res. 25:1315-1316.

7.Sambrook, J., E.F. Fritsch, and T. Maniatis. 1989. Molecular Cloning: A Laboratory Manual, 2nd ed. CSH Laboratory Press, Cold Spring Harbor, NY.

8.Skowronski, E.W., N. Armstrong, G. Anderson, M. Macht, and P.M. McCready. 2000. Magnetic, microplate-format plasmid isolation protocol for high-yield, sequencing-grade DNA. BioTechniques 29:786-792.

9. Yanisch-Perron, D., J. Vieira, and J. Messing. 1985. Improved M13 phage cloning vectors and host strains: nucleotide sequences of the M13mp18 and pUC19 vectors. Gene 33:103-119.

Address correspondence to Dr. Dylan Harris, Millipore, 17 Cherry Hill Drive, Danvers, MA 01923, USA. e-mail: dylan_harris@millipore.com

For reprints of this or any other article, contact Reprints@BioTechniques.com 